\title{
A Mathematical Model for the Dynamics of Hepatitis C
}

\author{
R. AVENDAN̄O ${ }^{\mathrm{a}}$, L. ESTEVA ${ }^{\mathrm{b}, *}$, J.A. FLORES ${ }^{\mathrm{b}}$, J.L. FUENTES ALLEN ${ }^{\mathrm{c}}$, G. GÓMEZ $^{\mathrm{b}}$ and JE. LÓPEZ-ESTRADA ${ }^{\mathrm{b}}$ \\ ${ }^{a}$ Educación Médica, Centro Médico Nacional Siglo XXI, IMSS, 06720, Mexico, D.F.; ${ }^{\circ}$ Depto. De Matemáticas, Fac. de Ciencias, UNAM, 04510, Mexico, \\ D.F.; ${ }^{\mathrm{c}}$ Hospital de Infectología, Centro Médico la Raza, IMSS, Mexico, D.F.
}

(Received 27 September 2000; In final form 21 May 2001)

\begin{abstract}
We formulate a model to describe the dynamics of hepatitis $\mathrm{C}$ virus (HCV) considering four populations: uninfected liver cells, infected liver cells, HCV and T cells. Analysis of the model reveals the existence of two equilibrium states, the uninfected state in which no virus is present and an endemically infected state, in which virus and infected cells are present. There exists a threshold condition that determines the existence and stability of the endemic equilibrium. We discuss the efficacy of the therapy methods for hepatitis $C$ in terms of the threshold parameter. Success of the therapy could possibly be predicted from the early viral dynamics in the patients.
\end{abstract}

Keywords: Hepatits C; Therapy; Threshold; Uninfected steady state; Endemically infected steady state

\section{INTRODUCTION}

Infection with hepatitis $\mathrm{C}$ virus (HCV) represents a public health problem with an alarming prevalence $(2-15 \%)$ throughout the world (Neumann et al., 1998). The existence of hepatitis C was not appreciated until 1975, when the application of recently developed diagnostic test for hepatitis A and B revealed that many cases were neither hepatitis A nor hepatitis B. The causative agent was identified in 1989 (Purcell, 1994).

The HCV is commonly transmitted via blood and blood products. Its transmission by other routes as unprotected sex, perinatal transmission from infected mother to offspring, etc. have been proposed but remain controversial and probably of minor importance.

The incubation period of hepatitis $\mathrm{C}$ averages 50 days. Acute hepatitis $\mathrm{C}$ is generally a mild disease with a mortality rate of $1 \%$. However, more than $50 \%$ of acute cases progress to chronicity, and some of them will eventually evolve to cirrhosis or hepatocellular carcinoma, or both (Purcell, 1994).

In acute infection, the most common symptom is fatigue. However, the majority of cases (up to 90\%) are asymptomatic. This makes the diagnosis of hepatitis $\mathrm{C}$ very difficult.

The current treatment for hepatitis $\mathrm{C}$ consists in the application of interferon (IFN) $\alpha-2 b$ with dose from 3 to 15 million international units (mlU). However, the treatment with IFN is successful in only $11-30 \%$ cases. In Neumann et al. (1998) an analysis of the efficacy of IFN- $\alpha$ therapy is presented. In addition, it has been reported that IFN used in combination with ribavirin (another antiviral agent) is more effective than the treatment with only IFN (Purcell, 1994). No vaccine is available for hepatitis $\mathrm{C}$, since a major obstacle to vaccine development is the probability of extensive antigenic variation between different strains (Lemon and Brown, 1995).

Appropriate mathematical models can be helpful to answer biologically important questions concerned with pathogenesis, the dynamics of the immune response and effectiveness of drug treatment. Models to understand the immune response to persistent virus and effectiveness of drug therapy have been formulated by several authors. Thus, Nowak and Bangham (1996) used a simple mathematical approach to explore the effects of individual variation in immune responsiveness on virus load and diversity. They found that a better indicator of CTL responsiveness is the equilibrium virus load, rather than the abundance of virus specific CTLs. Nowak et al. (1996) formulated a model that provided a quantitative understanding of HBV replication dynamics. Their analysis had implication for the optimal timing of drug treatment and immunotherapy in chronic HBV infection. Payne et al. (1996) formulated a model of hepatitis B virus infection to address important features of the infection, namely the

*Corresponding author. E-mail: lesteva@servidor.unam.mx 
wide manifestations of the infection and the age dependence thereof, and the typically long delay before the development of virus-induced liver cancer. Bonhoeffer et al. (1997) analyzed the dynamics of virus populations, the role of the immune system and resistance of drug therapy in limiting virus abundance in infections with HIV or hepatitis B. Neumann et al. (1998) used a mathematical model to analyze the efficacy of treatment with IFN- $\alpha$ therapy.

In this paper, we formulate and analyze a model for the $\mathrm{HCV}$ dynamics. Our model is closely related to the models proposed in Nowak and Bangham (1996), Nowak et al. (1996), Payne et al. (1996), Bonhoeffer et al. (1997) and Neumann et al. (1998), but here we consider the immune response by adding the virus-specific $T$ cell population, and we make a global analysis of the model equations. As in Nowak and Bangham (1996), Nowak et al. (1996) and Bonhoeffer et al. (1997), we find a threshold parameter $R_{0}$ (the basic reproductive number of the virus) which determines the dynamical behavior of the infection. This parameter is further used to account for the efficacy of hepatitis $\mathrm{C}$ therapy.

\section{THE MODEL}

Before the formulation of the model we remark some facts about the immune response to hepatitis C. Antibodies, cytokines, natural killer cells and $\mathrm{T}$ cells are essential components of a normal immune response to virus. For $\mathrm{HCV}$, infected individuals generally develop antibodies reactive with the core $(\mathrm{C})$ protein as well as several nonstructural protein antigens of HCV. However, there is no evidence that HCV antibodies, even when present in high serum titers protect against new cell infections or progression of the disease (Lemon and Brown, 1995).

On the other hand, CD8 + cytotoxic T lymphocytes have been identified in the liver of chronically infected humans and chimpanzees (Lemon and Brown, 1995). These cells are activated by a signal given by the virus to the immune system, either on the surface of the infected cells or on antigen-presenting cells. However, the relative contribution of $\mathrm{T}$ cells response to immunity and to disease pathogenesis remains uncertain. It is apparent that they are not capable of eliminating the infection (Lemon and Brown, 1995).

Here, we will consider only T cells response. One of the questions that we want to address by mathematical models is how important is this response on the dynamics of the infection.

Our model contains four variables: healthy liver cells $H_{\mathrm{s}}$ or target cells, infected liver cells $H_{\mathrm{i}}$, virus load $V$, and $\mathrm{CD} 8+$ cytotoxic $\mathrm{T}$ cells. The assumptions are the following.

Healthy liver cells $H_{\mathrm{s}}$ are produced at a constant rate $\beta_{\mathrm{s}}$ and die at a constant rate $\mu_{\mathrm{s}} ; H_{\mathrm{s}}$ cells become infected at a rate proportional to the product of $H_{\mathrm{s}}$ and $V$, with constant of proportionality $k$, and once infected die with a constant rate $\mu_{\mathrm{i}}$; T cells kill infected cells $H_{\mathrm{i}}$ at a rate proportional to the product of $H_{\mathrm{i}}$ and $T$, with constant of proportionality $\delta$.

Even when the acute HCV infection appears to be lytic, for chronic $\mathrm{HCV}$ infection it is not completely clear whether the virus is intrinsically cytopatic in infected hepatocytes. However, it appears more likely that the liver damage is immunologically mediated, as in chronic hepatitis B. Hepatocellular damage is probably initiated by the activation of virus-specific cytotoxic $\mathrm{T}$ cells (Lemon and Brown, 1995). Then it is reasonable to assume that the average life time of infected cells $\left(1 / \mu_{\mathrm{i}}\right)$ is shorter than the average life-time of healthy cells $\left(1 / \mu_{\mathrm{s}}\right)$. Thus, in the following we will assume $\mu_{\mathrm{i}} \geq \mu_{\mathrm{s}}$.

Hepatitis $\mathrm{C}$ virions are produced inside the infected cells at a rate of $p$ virions per infected cell per day. On the other hand, viruses die at a per capita constant rate $\mu_{\mathrm{v}}$.

In the presence of $\mathrm{HCV}$, supply of new $\mathrm{T}$ cells is given by

$$
\beta_{\mathrm{T}} V\left(1-\frac{T}{T_{\max }}\right),
$$

where $\beta_{\mathrm{T}}$ is the rate of growth of $\mathrm{T}$ cells, $T_{\max }$ is the maximum $\mathrm{T}$ cell population level. On the other hand $\mathrm{T}$ cells die at a per capita constant rate $\mu_{\mathrm{T}}$.

These assumptions lead to the following differential equations:

$$
\begin{gathered}
\dot{H}_{\mathrm{s}}=\beta_{\mathrm{s}}-k H_{\mathrm{s}} V-\mu_{\mathrm{s}} H_{\mathrm{s}} \quad \dot{H}_{\mathrm{i}}=k H_{\mathrm{s}} V-\delta H_{\mathrm{i}} T-\mu_{\mathrm{i}} H_{\mathrm{i}} \\
\dot{V}=p H_{\mathrm{i}}-\mu_{\mathrm{v}} V \quad \dot{T}=\beta_{\mathrm{T}} V\left(1-\frac{T}{T_{\mathrm{max}}}\right)-\mu_{\mathrm{T}} T
\end{gathered}
$$

All parameters in the model are positive. It is a simple matter to verify that Eq. (1) satisfy the existence and uniqueness conditions. Moreover, the region

$$
\begin{aligned}
\Omega & =\left\{\left(H_{\mathrm{s}}, H_{\mathrm{i}}, V, T\right) \in R_{+}^{4} \mid H_{\mathrm{s}}+H_{\mathrm{i}} \leq H_{\mathrm{M}}, V \leq V_{\mathrm{M}}, T\right. \\
& \left.\leq T_{\mathrm{M}}\right\}
\end{aligned}
$$

where $H_{\mathrm{M}}=\beta_{\mathrm{s}} / \mu_{*}, \quad V_{\mathrm{M}}=\left(p / \mu_{\mathrm{V}}\right) H_{\mathrm{M}}, \quad$ and $\quad T_{\mathrm{M}}=$ $\left(\beta_{\mathrm{T}} / \mu_{\mathrm{T}}^{*}\right) V_{\mathrm{M}}$ with $\mu_{\mathrm{T}}^{*}=\mu_{\mathrm{T}}+\left(\beta_{\mathrm{T}} / T_{\max }\right) V_{\mathrm{M}}$, is positively invariant for system (1), because the vector field on the boundary does not pint to the exterior. Therefore, solutions starting in $\Omega$ will remain there for $t \geq 0$. In the following we will assume that initial conditions are always given in $\Omega$.

Remark. We observe that $H_{\mathrm{M}}$ is the maximum number of cells in a healthy liver, therefore $V_{\mathrm{M}}$ is maximum virus load supported by an organism. On the other hand $T_{\mathrm{M}}<$ $T_{\max }$ represents the maximum number of $\mathrm{T}$ cells generated in an individual with hepatitis $\mathrm{C}$.

\section{EQUILIBRIUM SOLUTIONS}

We now show that in $\Omega$ there are two possible steady states, one with no virus present, an uninfected steady 
state, and another with a constant level of virus, an endemically infected steady state.

The equilibrium solutions of (1) must satisfy the following algebraic equations.

$0=\beta_{\mathrm{s}}-k H_{\mathrm{s}} V-\mu_{\mathrm{s}} H_{\mathrm{s}} \quad 0=k H_{\mathrm{s}} V-\delta H_{\mathrm{i}} T-\mu_{\mathrm{i}} H_{\mathrm{i}}$

$0=p H_{\mathrm{i}}-\mu_{\mathrm{V}} V \quad 0=\beta_{\mathrm{T}} V\left(1-\frac{T}{T_{\max }}\right)-\mu_{\mathrm{T}} T$.

From the first, third and fourth equations of (2), it can be seen that the equilibrium points satisfy the following relations

$$
\begin{aligned}
H_{\mathrm{s}}^{*} & =\frac{\beta_{\mathrm{s}}}{k V^{*}+\mu_{\mathrm{s}}}, \\
H_{\mathrm{i}}^{*} & =\frac{\mu_{\mathrm{V}} V^{*}}{p}, \\
T^{*} & =\frac{\beta_{\mathrm{T}} T_{\max } V^{*}}{\beta_{\mathrm{T}} V^{*}+\mu_{\mathrm{T}} T_{\max }} .
\end{aligned}
$$

If $V^{*}=0$, we obtain the uninfected steady state solution

$$
I_{0}=\left(\frac{\beta_{\mathrm{s}}}{\mu_{\mathrm{s}}}, 0,0,0\right)
$$

in which there is no infection. Consequently, all hepatic cells are healthy and $H_{\mathrm{s}}^{*}=\beta_{\mathrm{s}} / \mu_{\mathrm{s}}$ is the number of liver cells in a healthy individual.

If $V^{*} \neq 0$, then substituting $H_{\mathrm{s}}^{*}, H_{\mathrm{i}}^{*}$, and $T^{*}$ in the second equation of system (2), we obtain after some calculations that $V^{*}$ must satisfy the following quadratic equation

$$
r\left(V^{*}\right)=A V^{* 2}+B V^{*}+C
$$

with coefficients given by

$$
\begin{aligned}
A= & k \beta_{\mathrm{T}} \mu_{\mathrm{V}}\left(\delta T_{\text {max }}+\mu_{\mathrm{i}}\right), \\
B= & -k \beta_{\mathrm{s}} \beta_{\mathrm{T}} p+\delta \beta_{\mathrm{T}} \mu_{\mathrm{s}} \mu_{\mathrm{V}} T_{\max }+k \mu_{\mathrm{i}} \mu_{\mathrm{V}} \mu_{\mathrm{T}} T_{\max } \\
& +\beta_{\mathrm{T}} \mu_{\mathrm{i}} \mu_{\mathrm{s}} \mu_{\mathrm{V}}, \\
C= & \mu_{\mathrm{i}} \mu_{\mathrm{s}} \mu_{\mathrm{V}} \mu_{\mathrm{T}} T_{\text {max }}-k \beta_{\mathrm{s}} p \mu_{\mathrm{T}} T_{\text {max }} .
\end{aligned}
$$

Now, we see conditions such that Eq. (4) has a solution $0<V^{*}<V_{\mathrm{M}}$.

First, note that

$$
\begin{aligned}
r\left(V_{\mathrm{M}}\right)= & \frac{k \beta_{\mathrm{s}}^{2} \beta_{\mathrm{T}} p^{2} \delta T_{\max }}{\mu_{\mathrm{s}}^{2} \mu_{\mathrm{V}}}+\frac{k \beta_{\mathrm{s}}^{2} \beta_{\mathrm{T}} p^{2}}{\mu_{\mathrm{s}} \mu_{\mathrm{V}}}\left[\frac{\mu_{\mathrm{i}}}{\mu_{\mathrm{s}}}-1\right] \\
& +\delta \beta_{\mathrm{s}} \beta_{\mathrm{T}} p T_{\max }+\beta_{\mathrm{s}} \beta_{\mathrm{T}} p \mu_{\mathrm{i}}+\mu_{\mathrm{i}} \mu_{\mathrm{s}} \mu_{\mathrm{V}} \mu_{\mathrm{T}} T_{\max } \\
& +k \beta_{\mathrm{s}} p \mu_{\mathrm{T}} T_{\max }\left[\frac{\mu_{\mathrm{i}}}{\mu_{\mathrm{s}}}-1\right]
\end{aligned}
$$

and

$$
\begin{aligned}
\dot{r}\left(V_{\mathrm{M}}\right)= & \frac{2 k \beta_{\mathrm{s}} \beta_{\mathrm{T}} p \delta T_{\max }}{\mu_{\mathrm{s}}}+k \beta_{\mathrm{s}} \beta_{\mathrm{T}} p\left[\frac{2 \mu_{\mathrm{i}}}{\mu_{\mathrm{s}}}-1\right] \\
& +\delta \beta_{\mathrm{T}} \mu_{\mathrm{s}} \mu_{\mathrm{V}} T_{\max }+k \mu_{\mathrm{i}} \mu_{\mathrm{V}} \mu_{\mathrm{T}} T_{\max }+\beta_{\mathrm{T}} \mu_{\mathrm{i}} \mu_{\mathrm{s}} \mu_{\mathrm{V}}
\end{aligned}
$$

are bigger than zero since $\mu_{\mathrm{i}} \geq \mu_{\mathrm{s}}$, and all the coefficients are non-negative. Then, the existence of positive solutions of Eq. (4) will depend on the sign of $r(0)$ and $r(0)$. We have the following cases: (a) $r(0)>0$. In this case it is easy to see that $r(0)=C>0$ implies $\dot{r}(0)=B>0$, therefore Eq. (4) has no solutions $0<V^{*}<V_{\mathrm{M}}$. (b) $r(0)=0$. In this other case we have that $\dot{r}(0)>0$, and therefore the only positive root is $V^{*}=0$. (c) $r(0)<0$. Clearly in this case there exists a unique root $0<V^{*}<V_{\mathrm{M}}$.

From (2) it is easy to verify that if $0<V^{*}<V_{\mathrm{M}}$, then the non-trivial equilibrium $I_{1}=\left(H_{\mathrm{s}}^{*}, H_{\mathrm{i}}^{*}, V^{*}, T^{*}\right) \in \Omega$. Note also that $C<0$ is equivalent to $\frac{k \beta_{\mathrm{s}} p}{\mu_{\mathrm{i}} \mu_{\mathrm{s}} \mu_{\mathrm{V}}}>1$. Then, summarizing we have the following theorem.

THEOREM 1. Let $R_{0}$ be given by

$$
R_{0} \equiv \frac{k \beta_{\mathrm{s}} p}{\mu_{\mathrm{i}} \mu_{\mathrm{s}} \mu_{\mathrm{V}}}
$$

If $R_{0} \leq 1$, then $I_{0}=\left(\left(\beta_{\mathrm{s}} / \mu_{\mathrm{s}}\right), 0,0,0\right)$ is the only equilibrium point in $\Omega$; if $R_{0}>1$ then the endemically infected equilibrium

$$
\begin{aligned}
I_{1} & =\left(H_{\mathrm{s}}^{*}, H_{\mathrm{i}}^{*}, V^{*}, T^{*}\right) \\
& =\left(\frac{\beta_{\mathrm{s}}}{k V^{*}+\mu_{\mathrm{s}}}, \frac{\mu_{\mathrm{V}} V^{*}}{p}, V^{*}, \frac{\beta_{\mathrm{T}} T_{\max } V^{*}}{\beta_{\mathrm{T}} V^{*}+\mu_{\mathrm{T}} T_{\max }}\right)
\end{aligned}
$$

will also lie in $\Omega$.

The threshold parameter $R_{0}$ defined by (5) is called the basic reproductive number of the virus. The value of this parameter plays a central role in the dynamics of system (1) with important implications in the treatment of hepatitis $\mathrm{C}$.

The parameter $R_{0}$ has an interesting biological meaning: assume that an initial virus load $V_{0}$ is introduced in a healthy organism with $\beta_{\mathrm{s}} / \mu_{\mathrm{s}}$ healthy liver cells. These viruses produce in average, $\left(k \beta_{\mathrm{s}} / \mu_{\mathrm{s}} \mu_{\mathrm{V}}\right) V_{0}$ infected cells during their lifespan. Since each infected cell produces $p / \mu_{\mathrm{i}}$ virions during its lifespan, $\left(k \beta_{\mathrm{s}} p / \mu_{\mathrm{i}} \mu_{\mathrm{V}} \mu_{\mathrm{s}}\right) V_{0}=$ $R_{0} V_{0}$ is the average number of new virions produced by the initial virus load $V_{0}$ in a healthy organism.

It is worthy to observe that $R_{0}$ depends only on six of the ten parameters in the model.

\section{STABILITY OF THE UNINFECTED STEADY STATE}

In this section, we study the stability properties of the trivial or uninfected equilibrium state $I_{0}$. The Jacobian 
matrix $J\left(H_{\mathrm{s}}, H_{\mathrm{i}}, V, T\right)$ of system (1) is given by

$$
\left(\begin{array}{cccc}
-k V-\mu_{\mathrm{s}} & 0 & -k H_{\mathrm{s}} & 0 \\
k V & -\delta T-\mu_{\mathrm{i}} & k H_{\mathrm{S}} & -\delta H_{\mathrm{i}} \\
0 & p & -\mu_{\mathrm{V}} & 0 \\
0 & 0 & \beta_{\mathrm{T}}\left(1-\frac{T}{T_{\max }}\right) & -\frac{\beta_{\mathrm{T}} V}{T_{\max }}-\mu_{\mathrm{T}}
\end{array}\right)
$$

Then, the local stability of $I_{0}$ is governed by the eigenvalues of the matrix

$$
J\left(I_{0}\right)=\left(\begin{array}{cccc}
-\mu_{\mathrm{s}} & 0 & -k \frac{\beta_{\mathrm{s}}}{\mu_{\mathrm{s}}} & 0 \\
0 & -\mu_{\mathrm{i}} & k \frac{\beta_{\mathrm{s}}}{\mu_{\mathrm{s}}} & 0 \\
0 & p & -\mu_{\mathrm{V}} & 0 \\
0 & 0 & \beta_{\mathrm{T}} & -\mu_{\mathrm{T}}
\end{array}\right)
$$

which clearly are $-\mu_{\mathrm{s}},-\mu_{\mathrm{T}}$ and the roots of the quadratic equation

$$
\lambda^{2}+\left(\mu_{\mathrm{i}}+\mu_{\mathrm{V}}\right) \lambda+\mu_{\mathrm{i}} \mu_{\mathrm{V}}\left(1-\frac{k \beta_{\mathrm{s}} p}{\mu_{\mathrm{s}} \mu_{\mathrm{V}} \mu_{\mathrm{i}}}\right)=0 .
$$

The other two eigenvalues of $J\left(I_{0}\right)$ have negative real part if and only if the coefficients of (9) are positive, and this occurs if and only if $R_{0}<1$. Therefore $I_{0}$ is locally asymptotically stable for $R_{0}<1$. We can actually show that it is globally asymptotically stable in $\Omega$ for $R_{0} \leq 1$. To prove this, we use the Lyapunov function

$$
U\left(H_{\mathrm{s}}, H_{\mathrm{i}}, V, T\right)=p H_{\mathrm{i}}+\mu_{\mathrm{i}} V .
$$

The orbital derivative of $U$ is given by

$$
\dot{U}=-\mu_{\mathrm{i}} \mu_{\mathrm{V}}\left[1-\frac{k p H_{\mathrm{s}}}{\mu_{\mathrm{i}} \mu_{\mathrm{V}}}\right] V-p \delta H_{\mathrm{i}} T \text {. }
$$

Since $H_{\mathrm{s}} \leq \beta_{\mathrm{s}} / \mu_{\mathrm{s}}$, the expression inside the bracket in (11) is non-negative for $R_{0} \leq 1$ and therefore $\dot{U} \leq 0$ in $\Omega$. The subset where $\dot{U}=0$ is defined by the equations

$$
\begin{array}{lll}
V=0 & H_{\mathrm{i}} T=0 & \text { if } R_{0}<1 \\
V=0 \text { or } H_{\mathrm{s}}=\frac{\beta_{\mathrm{s}}}{\mu_{\mathrm{s}}}, & H_{\mathrm{i}} T=0 & \text { if } R_{0}=1 .
\end{array}
$$

From inspection of system (1), it can be seen that the maximum invariant set contained in $\dot{U}=0$ is the plane $V=0, H_{\mathrm{i}}=0$. In this set system (1) becomes

$$
\dot{H}_{\mathrm{s}}=\beta_{\mathrm{s}}-\mu_{\mathrm{s}} H_{\mathrm{s}} \quad \dot{H}_{\mathrm{i}}=0 \quad \dot{V}=0 \quad \dot{T}=-\mu_{\mathrm{T}} T
$$

which implies that solutions started there tend to the equilibrium $I_{0}$ as $t$ goes to infinity. Therefore, applying LaSalle-Lyapunov Theorem (Hale, 1969) it follows that $I_{0}$ is locally stable and all trajectories starting in $\Omega$ approach $I_{0}$. Summarizing, we have proven the following
THEOREM 2. The uninfected steady state $I_{0}$ of system (1) is globally asymptotically stable in the region $\Omega$.

\section{STABILITY OF THE ENDEMICALLY INFECTED STATE}

For $R_{0}>1$, the equilibrium $I_{0}$ becomes an unstable hyperbolic point, and the endemically infected equilibrium, $I_{1}$ emerges in the region $\Omega$. The local stability of $I_{1}$ is given by the Jacobian of (1) evaluated in this point:

$$
\left(\begin{array}{cccc}
-k V^{*}-\mu_{\mathrm{s}} & 0 & -k H_{s}^{*} & 0 \\
k V^{*} & -\delta T^{*}-\mu_{\mathrm{i}} & k H_{s}^{*} & -\delta H_{i}^{*} \\
0 & p & -\mu_{\mathrm{V}} & 0 \\
0 & 0 & \beta_{\mathrm{T}}\left(1-\frac{T^{*}}{T_{\max }}\right) & -\frac{\beta_{\mathrm{\beta}} V^{*}}{T_{\max }}-\mu_{\mathrm{T}}
\end{array}\right) \text {, }
$$

that can be rewritten as

$$
\left(\begin{array}{cccc}
-\frac{\beta_{\mathrm{s}}}{H_{\mathrm{s}}^{*}} & 0 & -k H_{s}^{*} & 0 \\
k V^{*} & -\frac{k H_{\mathrm{s}}^{*} p}{\mu_{\mathrm{V}}} & k H_{\mathrm{s}}^{*} & -\delta H_{i}^{*} \\
0 & p & -\mu_{\mathrm{V}} & 0 \\
0 & 0 & \frac{\mu_{\mathrm{T}} T^{*}}{V^{*}} & -\frac{\beta_{\mathrm{T}} V^{*}}{T^{*}}
\end{array}\right)
$$

when we take into account the identities:

$$
\begin{aligned}
k V+\mu_{\mathrm{s}} & =\frac{\beta_{\mathrm{s}}}{H_{\mathrm{s}}^{*}}, \quad \delta T^{*}+\mu_{\mathrm{i}}=\frac{k H_{\mathrm{s}}^{*} V^{*}}{H_{\mathrm{i}}^{*}}, \\
\frac{V^{*}}{H_{\mathrm{i}}^{*}} & =\frac{p}{\mu_{\mathrm{V}}}, \quad \delta T^{*}+\mu_{\mathrm{i}}=\frac{k H_{\mathrm{s}}^{*} p}{\mu_{\mathrm{V}}}, \\
\beta_{\mathrm{T}}\left(1-\frac{T^{*}}{T_{\max }}\right) & =\frac{\mu_{\mathrm{T}} T^{*}}{V^{*}}, \quad \frac{\beta_{\mathrm{T}} V^{*}}{T_{\max }}+\mu_{\mathrm{T}}=\frac{\beta_{\mathrm{T}} V^{*}}{T^{*}},
\end{aligned}
$$

which are obtained from system (3). Hence, the characteristic polynomial of the linealized system is given by

$$
P(\lambda)=\operatorname{det}\left(\begin{array}{cccc}
-\frac{\beta_{\mathrm{s}}}{H_{\mathrm{s}}^{*}}-\lambda & 0 & -k H_{\mathrm{s}}^{*} & 0 \\
k V^{*} & -\frac{k H_{\mathrm{s}}^{*} p}{\mu_{\mathrm{V}}}-\lambda & k H_{\mathrm{s}}^{*} & -\delta H_{\mathrm{i}}^{*} \\
0 & p & -\mu_{\mathrm{V}}-\lambda & 0 \\
0 & 0 & \frac{\mu_{\mathrm{T} T} T^{*}}{V^{*}} & -\frac{\beta_{\mathrm{T}} V^{*}}{T^{*}}-\lambda
\end{array}\right)
$$


After some calculations we obtain

$$
P(\lambda)=\lambda^{4}+a_{1} \lambda^{3}+a_{2} \lambda^{2}+a_{3} \lambda+a_{4}
$$

with

$$
\begin{aligned}
a_{1}= & \mu_{\mathrm{V}}+\frac{\beta_{\mathrm{s}}}{H_{\mathrm{s}}^{*}}+\frac{\beta_{\mathrm{T}} V^{*}}{T^{*}}+\frac{k H_{\mathrm{s}}^{*} p}{\mu_{\mathrm{V}}}, \\
a_{2}= & \frac{\beta_{\mathrm{s}}}{H_{\mathrm{s}}^{*}}\left[\frac{\beta_{\mathrm{T}} V^{*}}{T^{*}}+\left(\mu_{\mathrm{V}}+\frac{k H_{\mathrm{s}}^{*} p}{\mu_{\mathrm{V}}}\right)\right] \\
& +\frac{\beta_{\mathrm{T}} V^{*}}{T^{*}}\left(\mu_{\mathrm{V}}+\frac{k H_{\mathrm{s}}^{*} p}{\mu_{\mathrm{V}}}\right), \\
a_{3}= & \delta \mu_{\mathrm{V}} \mu_{\mathrm{T}} T^{*}+k^{2} p H_{\mathrm{s}}^{*} V^{*} \\
& +\frac{\beta_{\mathrm{s}}}{H_{\mathrm{s}}^{*}} \frac{\beta_{\mathrm{T}} V^{*}}{T^{*}}\left(\mu_{\mathrm{V}}+\frac{k H_{\mathrm{s}}^{*} p}{\mu_{\mathrm{V}}}\right), \\
a_{4}= & \delta \mu_{\mathrm{V}} \mu_{\mathrm{T}} T^{*} \frac{\beta_{\mathrm{s}}}{H_{s}^{*}}+\frac{k^{2} p \beta_{\mathrm{T}} H_{s}^{*}\left(V^{*}\right)^{2}}{T^{*}} .
\end{aligned}
$$

Using the Routh-Hurwitz criteria (Gantmacher, 1960), the local stability of the endemic equilibrium $I_{1}$ will be established if we show that

$$
\Delta_{3}=\left|\begin{array}{ccc}
a_{1} & 1 & 0 \\
a_{3} & a_{2} & a_{1} \\
0 & a_{4} & a_{3}
\end{array}\right|=\left(a_{1} a_{2}-a_{3}\right) a_{3}-a_{1}^{2} a_{4}>0
$$

since the coefficients $a_{1}, a_{2}, a_{3}$ and $a_{4}$ of the characteristic polynomial $P(\lambda)$ are all positive.

To see that condition (14) is satisfied, it is convenient to adopt the following notation:

$$
\begin{aligned}
& A=\frac{\beta_{\mathrm{s}}}{H_{\mathrm{s}}^{*}}, \quad B=\frac{\beta_{\mathrm{T}} V}{T^{*}} \quad C=\frac{k H_{\mathrm{s}}^{*} p}{\mu_{\mathrm{V}}}, \quad D=\delta \mu_{\mathrm{V}} \mu_{\mathrm{T}} T^{*} \\
& E=k \mu_{\mathrm{V}} V^{*}, \quad F=C+\mu_{\mathrm{V}}, \quad G=\frac{\beta_{\mathrm{T}} V^{*}}{T_{\max }} .
\end{aligned}
$$

In terms of the variables above we rewrite the coefficients $a_{1}, a_{2}, a_{3}$ and $a_{4}$ as

$$
\begin{aligned}
& a_{1}=A+B+F, \\
& a_{2}=A B+a F+B F, \\
& a_{3}=A B F+C E+D, \\
& a_{4}=A D+B C E .
\end{aligned}
$$

After tedious calculations we obtain the following expression

$$
\begin{aligned}
\left(a_{1} a_{2}-\right. & \left.a_{3}\right) a_{3}-a_{1}^{2} a_{4} \\
= & A^{3} B^{2} F+A^{2} B D+A^{2} C E F+A^{2} B^{3} F \\
& +B^{2} D F+A^{3}\left(B F^{2}-D\right)+B^{3}\left(A F^{2}-C E\right) \\
& +2 A^{2} B\left(B F^{2}-D\right)-A B^{2} C E+A B F\left(B F^{2}-D\right) \\
& +A B F\left(A F^{2}-C E\right)-A^{2} D F-B^{2} C E F \\
& +C E\left(A F^{2}-C E\right)+D\left(B F^{2}-D\right)-2 C E D .
\end{aligned}
$$

On the other hand, from the equations in equilibrium (3) we obtain the relations:

$$
A=\frac{E}{\mu_{\mathrm{V}}}+\mu_{\mathrm{s}}, \quad D=C \mu_{\mathrm{V}} \mu_{\mathrm{T}}-\mu_{\mathrm{i}} \mu_{\mathrm{T}} \mu_{\mathrm{V}},
$$

and from them it is easy to see that the following inequalities are satisfied

$$
A F^{2}>2 E C, \quad B F^{2}>2 D, \quad B F^{2}>B C^{2} .
$$

Now, from (16) we have the following inequalities

$$
\begin{aligned}
2 A^{2} B\left(B F^{2}-D\right)-A B^{2} C E & A^{2} B\left(B F^{2}-2 D\right)+A B^{2}\left(A F^{2}-C E\right)>0 \\
A B F( & \left.B F^{2}-D\right)+A B F\left(A F^{2}-C E\right)-A^{2} D F \\
- & B^{2} C E F \\
= & A B F^{3}(A+B)-A B F(C E+D)-F\left(A^{2} D\right. \\
& \left.+B^{2} C E\right) \\
> & A B F^{3}(A+B)-A B F(C E+D) \\
& -F\left(\frac{A^{2} B F^{2}}{2}+\frac{B^{2} A F^{2}}{2}\right) \\
= & \frac{A B F^{3}(A+B)}{2}-A B F(C E+D) \\
= & A B F\left(\frac{A F^{2}}{2}-C E\right)+A B F\left(\frac{B F^{2}}{2}-D\right)>0
\end{aligned}
$$

and

$$
\begin{aligned}
& D\left(B F^{2}-D\right)+C E\left(A F^{2}-C E\right)-2 C D E \\
& \quad>D^{2}+(C E)^{2}-2 C D E=(D-C E)^{2} \geq 0
\end{aligned}
$$

From (17)-(19) it follows inequality (14). Therefore we have proved the following theorem. 

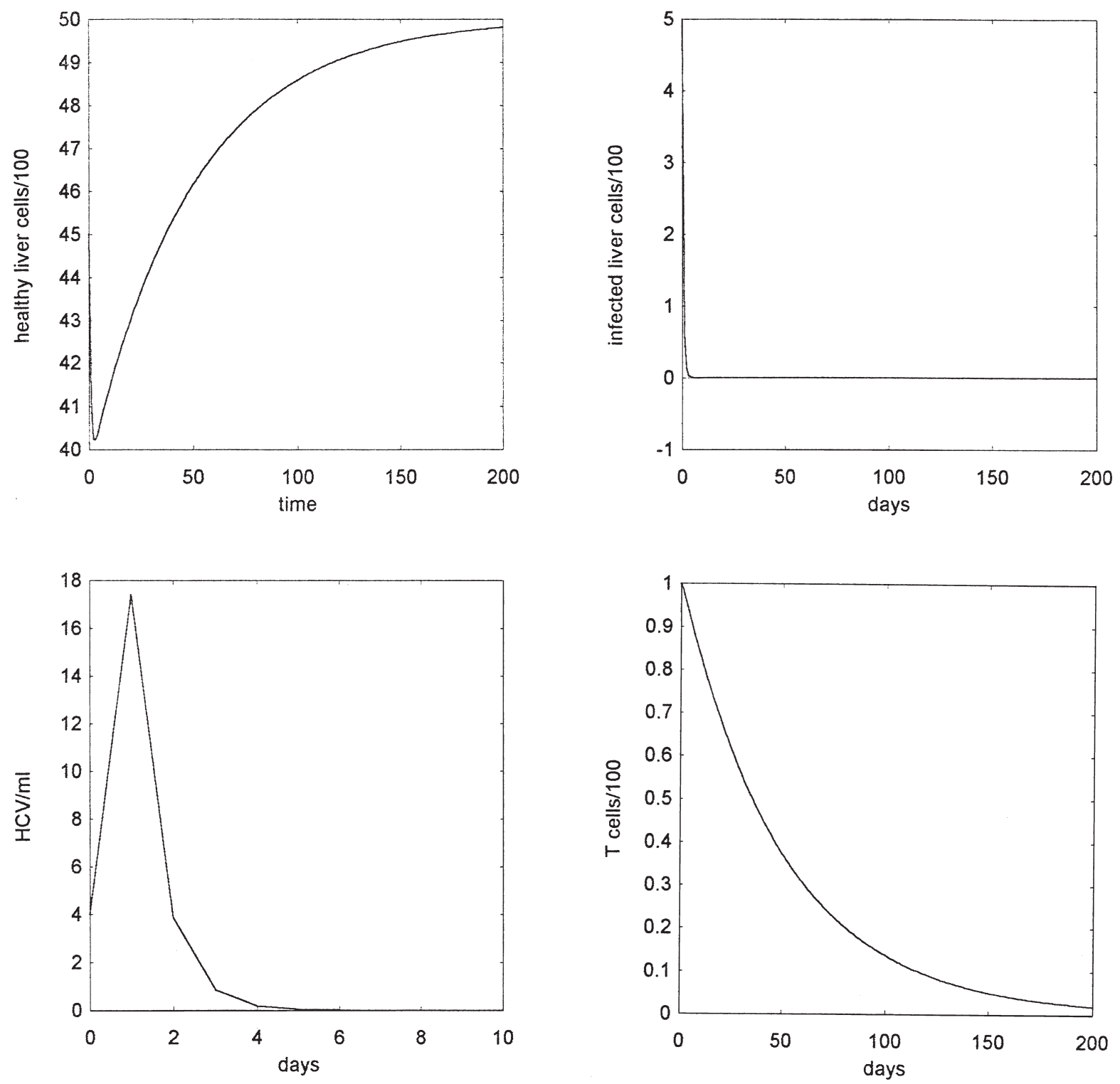

FIGURE 1 Numerical solution of model (1). The graphs show healthy liver cells, infected liver cells virus load and $\mathrm{T}$ cells versus time. The parameters in the simulation are: $\beta_{\mathrm{s}} / \mu_{\mathrm{s}}=5,000, \mu_{\mathrm{s}}=\mu_{\mathrm{T}}=0.02 /$ day, $\mu_{\mathrm{i}}=0.5 /$ day, $\mu_{\mathrm{V}}=5 /$ day, $k=0.00003, p=100$ virions per milimiter per cell per day, $\delta=0.00001, \beta_{\mathrm{T}}=0.0003$. In this case $R_{0}=0.6$.

THEOREM 3. For $R_{0}>$ the endemically infected state $\mathrm{I}_{1}$ is in $\Omega$ and it is locally asymptotically stable.

\section{DISCUSSION}

Starting with a description of healthy and infected liver cells $H_{\mathrm{s}}, H_{\mathrm{i}}$, virus load $V$ and virus specific T cells, we have developed a model for hepatitis $\mathrm{C}$ dynamics. While our model is overly simple in that it does not account for the immune response to $\mathrm{HCV}$ infection or mechanisms of cell death other than killing by cytotoxic $\mathrm{T}$ cells, it has some interesting predictions.

The basic reproductive number of the virus, $R_{0}$ has been used largely in understanding the persistence of viral infections within individuals (see for example Nowak,
1996 and Bonhoeffer et al., 1997), and in the population. For this model, $R_{0}=\beta_{\mathrm{s}} \mathrm{kp} / \mu_{\mathrm{i}} \mu_{\mathrm{s}} \mu_{\mathrm{V}}$ and it has to be above one for successful chronic HCV infection. If $R_{0} \leq 1$, then the level of virus load and infected cells will monotonically decrease and ultimately be eliminated. This decrease may be due to the fact, that virus does not infect enough cells, or infected cells die without producing a sufficient number of viral progeny. In this aspect, the model is similar to epidemiological models in which infected individuals must infect at least a critical number of individuals for an epidemic to occur. As in epidemiological models, we have two steady states, an uninfected steady state where the virus, infected cells and reactive $\mathrm{T}$ cells are not present; and an endemically infected steady state where all four populations of the model are maintained. 

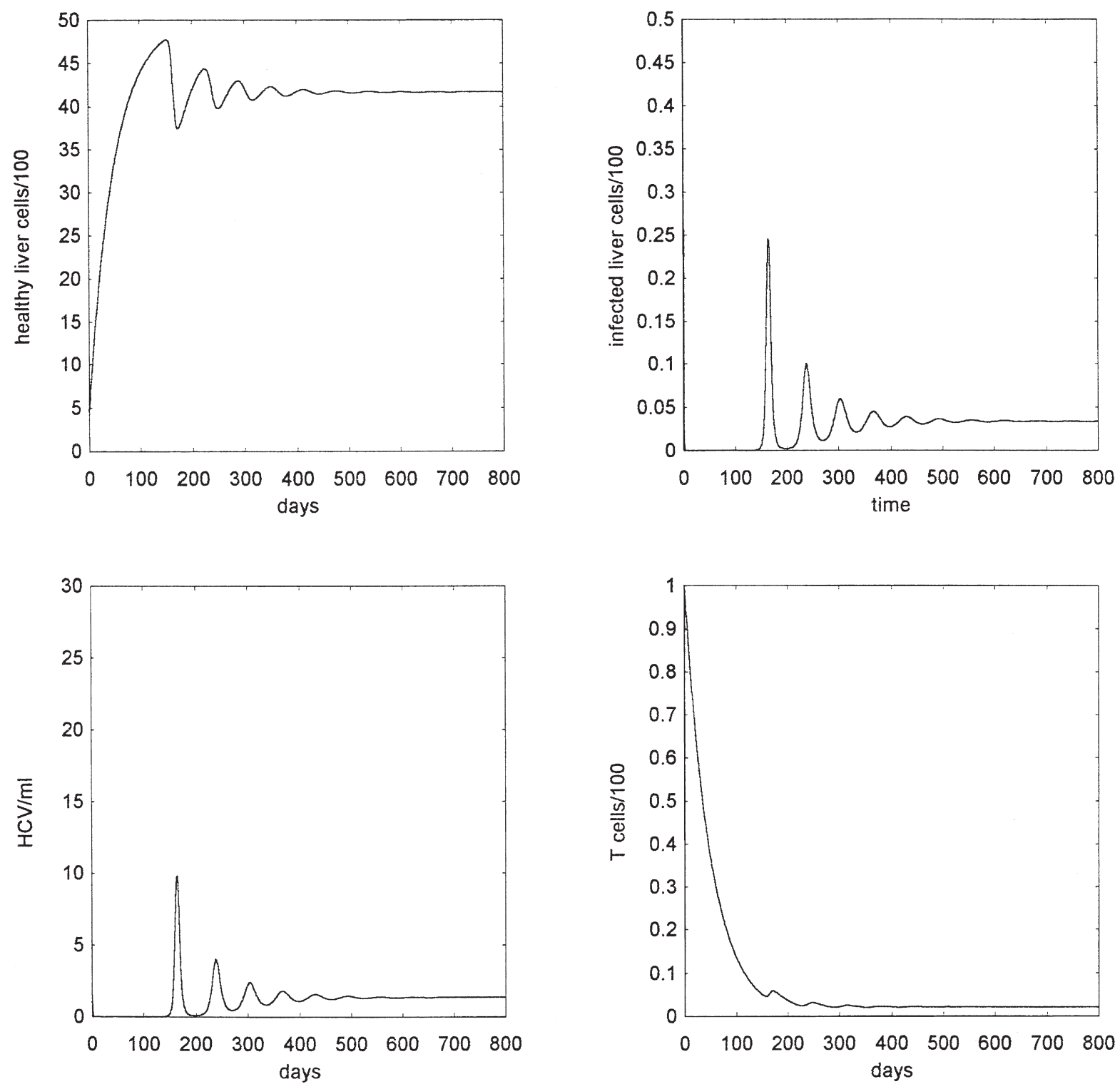

FIGURE 2 Numerical solution of model (1). The graphs show healthy liver cells, infected liver cells, virus load and T cells versus time. The parameters in the simulation are: $\beta_{\mathrm{s}} / \mu_{\mathrm{s}}=5,000, \mu_{\mathrm{s}}=\mu_{\mathrm{T}}=0.02 /$ day, $\mu_{\mathrm{i}}=0.5 /$ day, $\mu_{\mathrm{V}}=5 /$ day, $k=0.00003, p=200$ virions per millimeter per cell per day, $\delta=0.00001, \beta_{\mathrm{T}}=0.0003$. In this case $R_{0}=1.2$.

Figures. 1 and 2 illustrate the typical behavior of the healthy and infected liver cells, virus load and $\mathrm{T}$ cells initially positive. In Fig. $1 R_{0}=0.6$, whereas in Fig. 2, $R_{0}=1.2$. Notice that temporal courses of the liver cells and the virus load present damped oscillations.

One interesting feature of our model is that $R_{0}$ does not depend on the $\mathrm{T}$ cell immune response of the organism. It appears that activation of virus-specific $\mathrm{T}$ cells are more related with the liver damage in chronic hepatitis $\mathrm{C}$ (Lemon and Brown, 1995), and it is probably that the effect of the immune response is reflected in the mortality rate of infected cells $\mu_{\mathrm{i}}$.

Clinical studies has been done to document the efficacy of recombinant IFN- $\alpha$ in the treatment of chronic hepatitis C (Lemon and Brown, 1995; Poynard et al., 1998). Although IFN has been approved for treatment of chronic hepatitis $\mathrm{C}$, it has been showed that it is successful in only
$11-30 \%$ of the cases (Neumann et al., 1998), and the mechanism of action is not well understood. In a recent paper, Neumann et al. (1998) analyzed this problem. They hypothesized that IFN acts by blocking the production or release of virions rather than by blocking the novo infections. Using mathematical analysis coupled with clinical studies, they corroborated their hypothesis, and also they estimated the efficacy of IFN therapy, that is, the percentage of $\mathrm{HCV}$ production blocked by different doses of IFN. Furthermore, they estimated the infected cell rate.

In this paper, we use a more theoretical point of view to analyze the effects of the current treatment with IFN. It is clear that in order to control the disease (i.e. the virus load declines to zero), we have to reduce $R_{0}$ below the value one, and this can be achieved reducing $k$ or $p$ below critical values or increasing $\mu_{\mathrm{V}}$ or $\mu_{\mathrm{i}}$ above critical values. It is worth to note that $R_{0}$ is directly proportional to $k$ and $p$, and inversely 

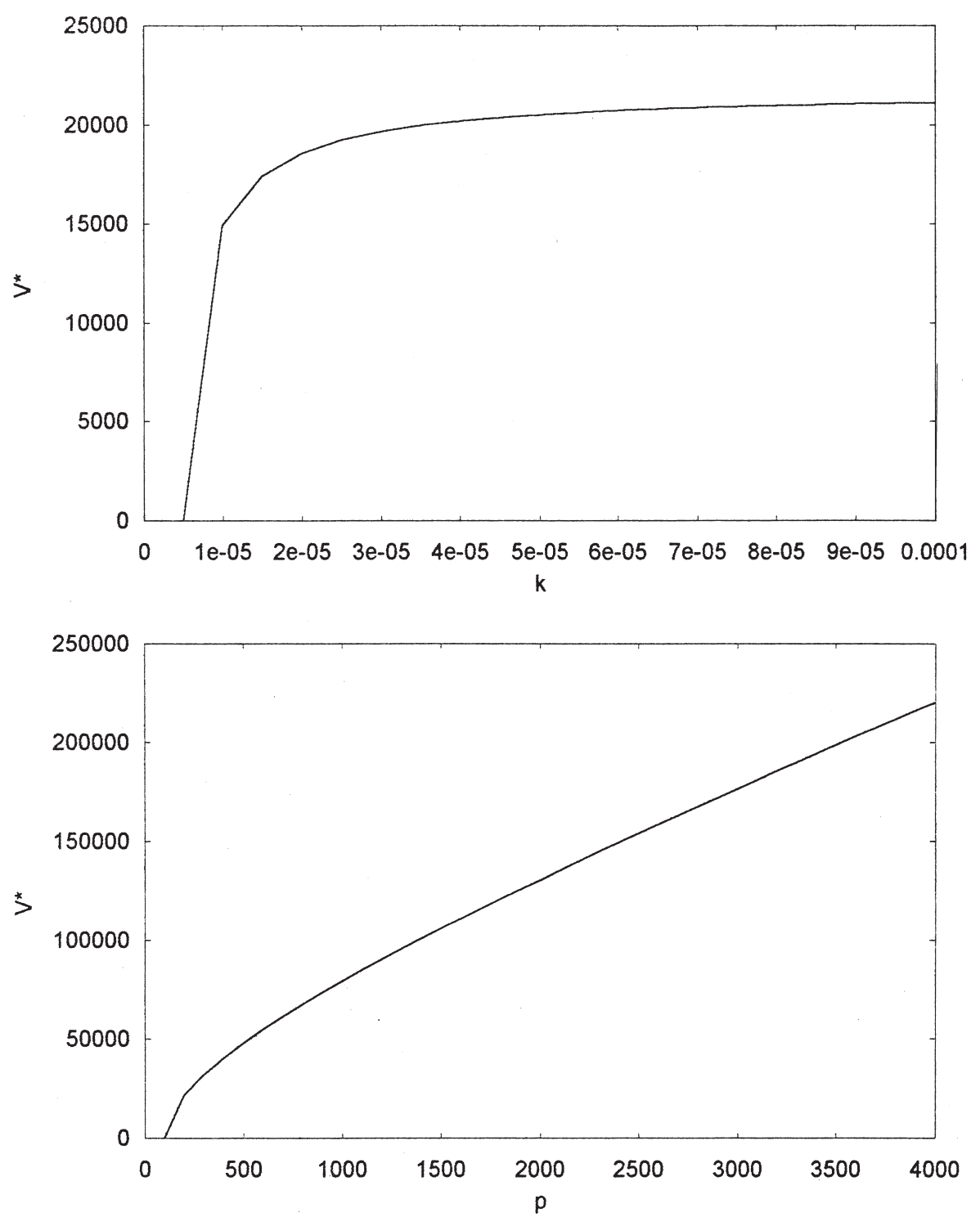

FIGURE $3 V^{*}$ vs. $k, p$, respectively. The initial values of the parameters for $V^{*}=0$ are: $\beta_{\mathrm{s}} / \mu_{\mathrm{s}}=5,000, \mu_{\mathrm{s}}=\mu_{\mathrm{T}}=0.02 /$ day, $\mu_{\mathrm{i}}=0.5 /$ day, $\mu_{\mathrm{V}}=5 /$ day, $k=0.00003, p=100$ virions per millimeter per cell per day, $\delta=0.00001, \beta_{\mathrm{T}}=0.0003$.

proportional to $\mu_{\mathrm{i}}, \mu_{\mathrm{V}}$, which implies that increasing the mortality of the infected cells and the free virus could be a mechanism to achieve a fast decrease in the virus load. Of course, this will depend on the range of the parameters.

Combination therapies that reduce the rate of "de novo" infections $k$, production rate of virions $p$ and at the same time rise the mortality of infected cells or virus, could be much more effective that the current therapy with IFN, which is assumed that essentially blocks production of new virons. Recent reports have suggested that ribavirin in combination with IFN is more effective that the treatment with only IFN (see Poynard et al., 1998). Studies on combination therapy are under way, but results are still inconclusive.

The model can be used to study the relation between the parameters involved in the infection and the endemic virus load. Endemic virus load is directly correlated with $k$ and $p$
(Fig. 3); and inversely correlated to $\mu_{\mathrm{i}}$ and $\mu_{\mathrm{V}}$ (Fig. 4). These correlations suggest that immune control through faster killing of infected cells or free virus may have an important role in lowering HCV load.

Also, Figs. 3 and 4 show that the magnitude of the variation virus load is sensible to the values of the parameters. Virus load increases for small values of $k$ and $p$, but saturates for large values of these parameters. On the other hand, for small values of $\mu_{\mathrm{i}}$ and $\mu_{\mathrm{V}}$, virus load decreases rapidly, but for larger values it remains almost constant. This suggests that strong or weak response to treatments depends on the state of viral, infection and immune parameters, and the success of the therapy could possibly the predicted from the early knowledge of these parameters in the patients.

Substituting the endemic values $V^{*} / H_{\mathrm{i}}^{*}=\frac{p}{\mu_{\mathrm{V}}}$ in the expression $R_{0}=1$ we obtain the equivalent threshold 

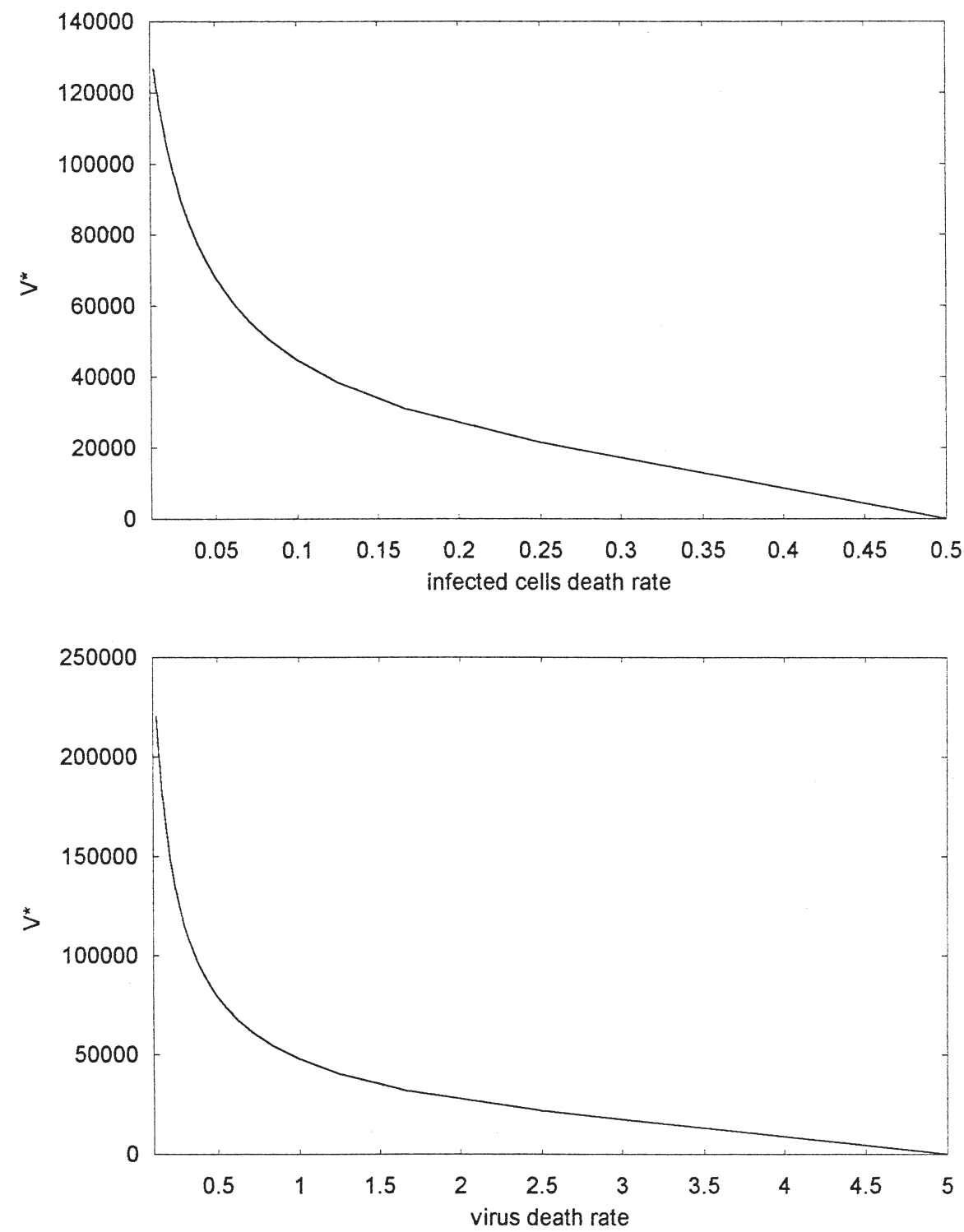

FIGURE $4 V^{*}$ vs. $\mu_{\mathrm{i}}$ and $\mu_{\mathrm{V}}$ respectively. The initial values of the parameters for $V^{*}=0$ are: $\beta_{\mathrm{s}} / \mu_{\mathrm{s}}=5,000, \mu_{\mathrm{s}}=\mu_{\mathrm{T}}=0.02 /$ day, $\mu_{\mathrm{i}}=0.5 /$ day, $\mu_{\mathrm{V}}=5 /$ day, $k=0.00003, p=100$ virions per millimeter per cell per day, $\delta=0.00001, \beta_{\mathrm{T}}=0.0003$.

condition for HCV infection

$$
\frac{V^{*}}{\bar{H}_{\mathrm{i}}^{*}}=\frac{\mu_{\mathrm{s}}}{k}
$$

where $\bar{H}_{\mathrm{i}}^{*}=\frac{H_{\mathrm{i}}^{*}}{\beta_{\mathrm{s}} / \mu_{\mathrm{s}}}$ is the proportion of infected cells. Theoretically, this means that in order to clear the infection, the quotient of the virus load and the proportion of infected cells has to be less or equal than the right hand side of Eq. (20). Now, $V^{*}$ and $\bar{H}_{\mathrm{i}}^{*}$ could be obtained from clinical tests and $k$ and $\mu_{\mathrm{s}}$ could be estimated from data (see Neumann et al., 1998) for an estimation of $\mu_{\mathrm{s}}$ ) in order to test the feasibility of this model.

\section{Acknowledgements}

We are grateful to the anonymous referees for their careful reading that helped us to improve the paper. LEP acknowledges support from CONACYT grant.

\section{References}

Bonhoeffer, S., May, R.M., Shaw, G.M. and Nowak, M.A. (1997) "Virus dynamics and drug therapy", Proc. Natl Acad. Sci. USA 94, 6971-6976.

Gantmacher, F.R. (1960) The Theory of Matrices Vol. 2.

Hale, J.K. (1969) Ordinary Differential Equations (Wiley, New York).

Lemon, S.M. and Brown, E.A. (1995) "Hepatitis C Virus", In: Mandell, G.L., Bennet, J.E. and Dolin, R., eds, Principles and Practice of Infectious Diseases, 4th Ed. (Churchill Livingstone Inc., New York), pp 1474-1483.

Neumann, A.U., Lam, N.P., Dahari, H., Gretch, D.R., Wiley, T.E., Layden, T.J. and Perelson, A.S. (1998) "Hepatitis C viral dynamics in vivo and the antiviral efficacy of interferon- $\alpha$ therapy", Science $\mathbf{2 8 2}$, $103-107$.

Nowak, M.A. and Bangham, C.R.M. (1996) "Population dynamics of immune responses to persistent viruses", Science 272, 74-79.

Nowak, M.A., Bonhoeffer, S., Hill, A.M., Boehme, R., Thomas, H.C. and McDade, H. (1996) "Viral dynamics in hepatitis B virus infection", Proc. Natl Acad. Sci. USA 93, 4398-4402.

Payne, R.J.H., Nowak, M.A. and Blumberg, B.S. (1996) "The dynamics of hepatitis B virus infection", Proc. Natl Acad. Sci. USA 93, $6542-6546$. 
Poynard, T., Marcellin, P., Lee, S.S., Niederau, Ch., Minuk, G.S., Ideo, G., Bain, V., Heathcote, J., Zeuzmen, S., Trepo, Ch. and Albrecht, J. (1998) "Randomized trail of interferon $\alpha-2 b$ plus ribavirin for 48 weeks or 24 weeks versus interferon $\alpha 2 b$ plus placebo for
48 weeks for treatment of chronic infection with hepatitis C virus", Lancet 352, 1426-1432.

Purcell, R.H. (1994) "Hepatitis viruses: Changing patterns of human disease", Proc. Natl Acad. Sci. USA 91, 2401-2406. 


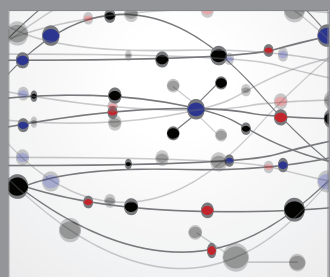

The Scientific World Journal
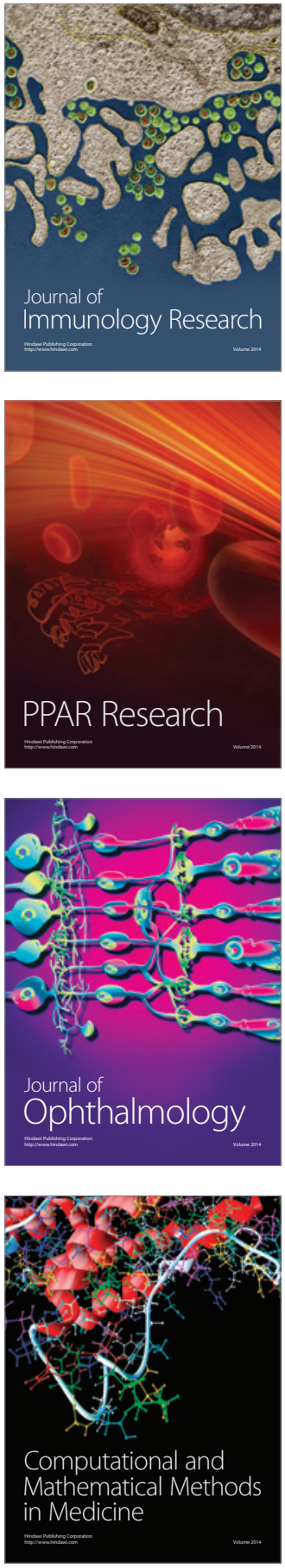

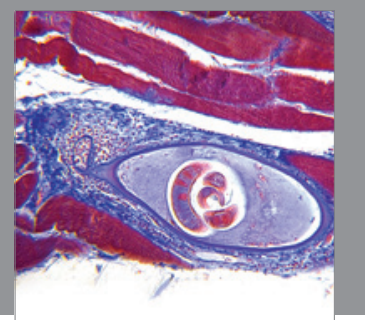

Gastroenterology

Research and Practice
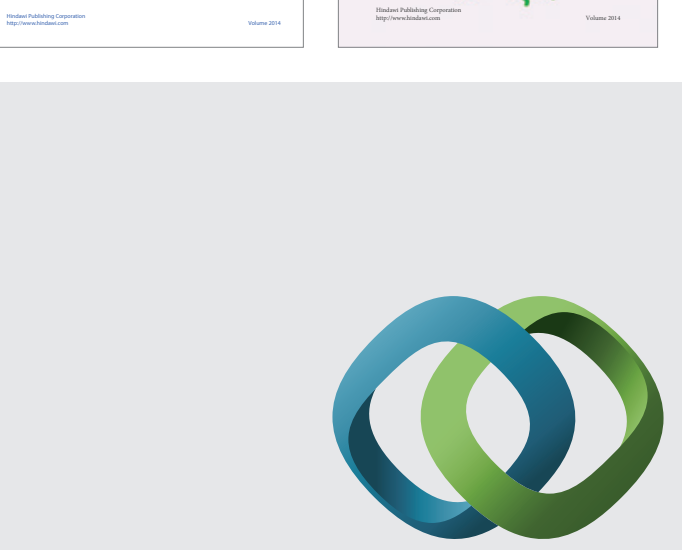

\section{Hindawi}

Submit your manuscripts at

http://www.hindawi.com
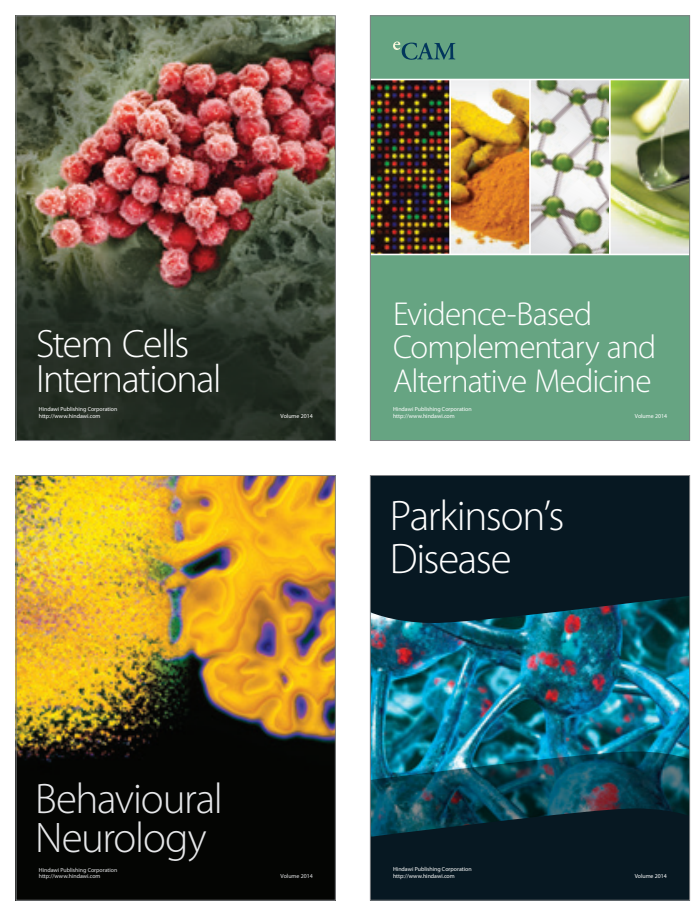

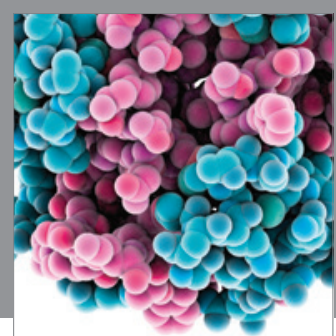

Journal of
Diabetes Research

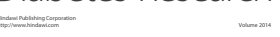

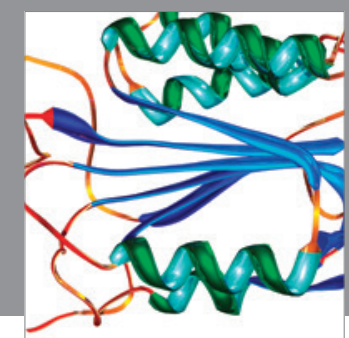

Disease Markers
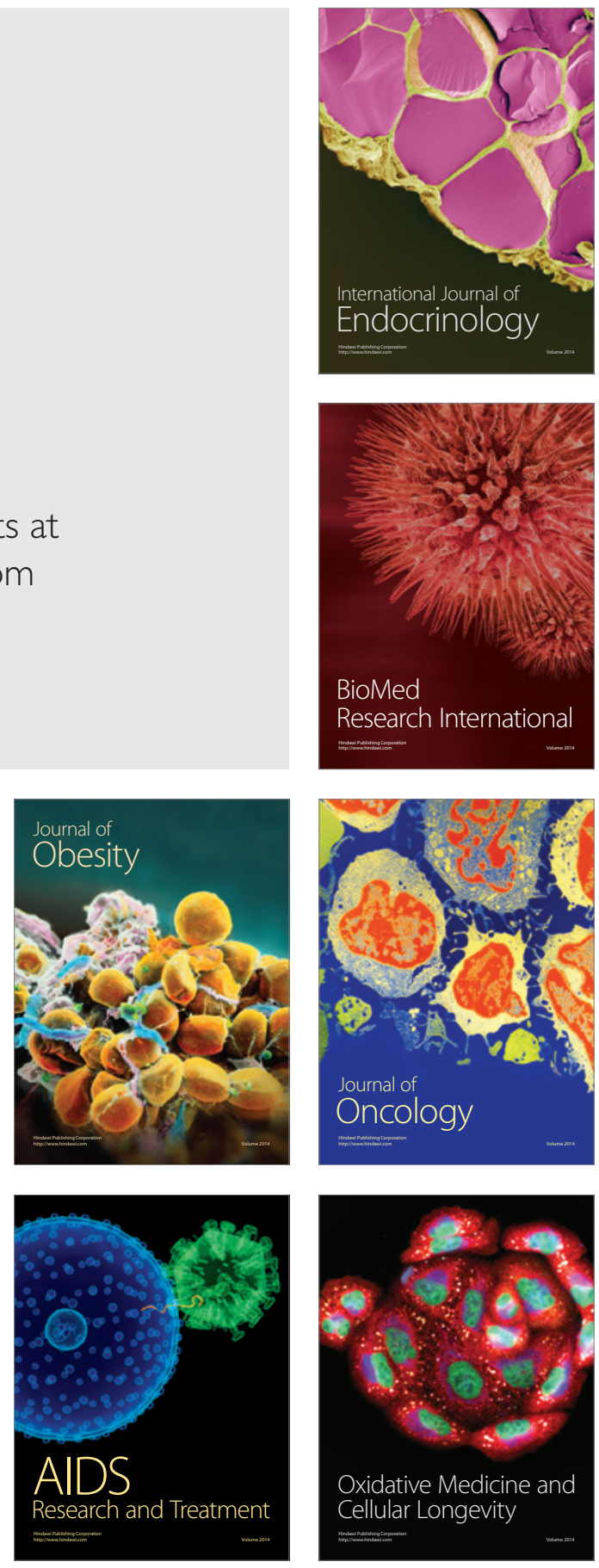